\title{
Immunomodulatory potential of gut microbiome-derived short- chain fatty acids (SCFAs)
}

\author{
Weronika Ratajczak ${ }^{\natural}$, Aleksandra Rył2, Arnold Mizerski³ ${ }^{3}$ Kinga Walczakiewicz', \\ Olimpia Sipak ${ }^{4}$ and Maria Laszczyńska ${ }^{1}$
}

'Department of Histology and Developmental Biology, Pomeranian Medical University, Szczecin, Poland; ${ }^{2}$ Department of Medical Rehabilitation and Clinical Physiotherapy, Pomeranian Medical University, Szczecin, Poland; ${ }^{3}$ Department of General Pharmacology and Pharmacoeconomics, Pomeranian Medical University, Szczecin, Poland; “Department of Obstetrics and Pathology of Pregnancy, Pomeranian Medical University, Szczecin, Poland

Intestinal microbiota is an element of the bacterial ecosystem in all mammalian organisms. These microorganisms play a very important part in the development, functioning, and modulation of the immune system from the moment of birth. In recent years, owing to the use of modern sequencing techniques, the microbiome composition in healthy people has been identified based on bacterial 16S rRNA analysis. Currently, more and more attention is being given to the influence of microorganisms on the host's cellular metabolism. Analysis of microbial metabolites, among them short-chain fatty acids (SCFAs), and disruption of intestinal microbiota homeostasis in terms of their effects on molecular regulatory mechanisms of immune reactions will surely improve the understanding of the etiology of many common diseases. SCFAs, mainly butyrate, propionate, and acetate, occur in specific amounts, and their proportions can change, depending on the diet, age and diseases. The levels of SCFAs are substantially influenced by the ratio of commensal intestinal bacteria, the disturbance of which (dysbiosis) can lead to a disproportion between the SCFAs produced. SCFAs are regarded as mediators in the communication between the intestinal microbiome and the immune system. The signal they produce is transferred, among others, in immune cells via free fatty acid receptors (FFARs), which belong to the family of G protein-coupled receptors (GPCRs). It has been also confirmed that SCFAs inhibit the activity of histone deacetylase (HDAC) - an enzyme involved in post-translational modifications, namely the process of deacetylation and, what is new, the process of histone crotonylation. These properties of SCFAs have an effect on their immunomodulatory potential i.e. maintaining the anti/ pro-inflammatory balance. SCFAs act not only locally in the intestines colonized by commensal bacteria, but also influence the intestinal immune cells, and modulate immune response by multi-protein inflammasome complexes. SCFAs have been confirmed to contribute to the maintenance of the immune homeostasis of the urinary system (kidneys), respiratory system (lungs), central nervous system, and the sight organ.

Key words: intestinal microbiota, dysbiosis, short-chain fatty acids (SCFAs), inflammation, inflammasome

Received: 19 November, 2018; revised: 22 January, 2019; accepted: 20 February, 2019; available on-line: 04 March, 2019

凶e-mail: weronika.ratajczak@pum.edu.pl

Abbreviations: SCFAs, short-chain fatty acids; C2, acetate; C3, propionate; 44 , butyrate; HDACs, histone deacetylases; TNF, tumor necrosis factor; FFAR2, free fatty acid receptor 2; FFAR3, free fatty acid receptor 3; LPS, bacterial lipopolysaccharides; AMPs, antimi- crobial peptides; $\mathrm{CCL}$, chemokines; Th1, type $1 \mathrm{~T}$ helper lymphocytes; Th1, T helper 17 lymphocytes; Treg, $T$ regulatory lymphocytes; NALP3, NACHT, LRR and PYD domains-containing protein 3; AIM2, Interferon-inducible protein AIM2 (absent in melanoma 2)

\section{INTRODUCTION}

As reviewed by Mackowiak (Mackowiak, 2013), studies of the role that intestinal microflora plays in maintaining the organism's homeostasis have been carried out for more than one hundred years. The century-long research on the human microbiome has confirmed that commensal bacteria found in various organs and integuments of the human body promote the pathogenesis of many diseases (Aragón et al., 2018; Evsyutina et al., 2017; Flemer et al., 2017; Porter et al., 2018).

The development and composition of the human gut microbiota are influenced by the type of labor and infant nutrition (Nagpal et al., 2017). In healthy neonates, the intestinal microflora changes from birth to the age of three. Initially, it mainly consists of facultative anaerobic bacteria from the Enterobacteriaceae family, Enterococcus, and Staphylococcus genera. The composition of this ecosystem alters as a result of children's growing up, the introduction of new foods in their diet, and exposure to environmental factors. Thus, when they reach the age of three, their intestinal microflora is represented by obligatory anaerobes, mostly Clostridium (C.) leptum, C. coccidoides, Bifidobacterium, and Bacteroides fragilis (Nagpal et al., 2017).

At present, methods for deep sequencing of bacterial genetic material from feces samples had let us establish which bacteria commonly occur in the intestines, irrespective of individual features, past diseases, diet, and environmental factors. The available studies show that each person has their stable bacterial metagenome-the collective genome of microorganisms from the gut environment that provides information on the microbial diversity and ecology of this specific environment (niche). As reviewed by Maynarda and others (Maynard et al., 2012) and Iebba and others (Iebba et al., 2016), the presence of diverse but balanced intestinal microflora is defined as eubiosis, which is characterized by a predominance of beneficial microbiota species, mainly belonging to two phyla - Bacteroidetes and Firmicutes. Although pathogenic species may be present, they are in the minority. Moreover, in the eubiotic state, the immune homeostasis of the intestinal mucous membrane and the gut-associated lymphoid tissue (GALT) is maintained. This is so because microorganism-associated molecular patterns (MAMPs) stimulate secretion of cytokines in- 
volved in the differentiation of dendritic cells and macrophages, which results in the activation of Treg cells. Their activity manifests as secretion of IL-10, involved in the development of an anti-inflammatory environment. Additionally, transforming growth factor- $\beta$ (TGF- $\beta$ ), also secreted by Treg lymphocytes, stimulates plasma cells to secrete immunoglobulin A (IgA). Individual metagenomes (mainly including bacteria from the Bacteroidetes and Firmicutes phyla) may slightly deviate from the one shared by the whole population. The presence of such a specific and stable microbiome ensures the smooth functioning of the whole intestinal ecosystem, undergoing modifications throughout the adult life (Qin et al., 2010). The intestinal balance between Bacteroidetes and Firmicutes may not be a defining attribute of an individual's intestinal microbiome. Instead, individuals have their own 'personal equilibrium' between Bacteroidetes and temporally variable Firmicutes (Lloyd-Price et al., 2017; Claesson et al., 2011). Composition of the human intestinal microflora has an effect on the maintenance of health, but its role in many pathological states is also taken into consideration (Holmes et al., 2012). Microflora influences the host's health through microbial components, such as polysaccharide A (PSA) (Mazmanian et al., 2008), formyl peptides (Bufe et al., 2015), D-glycero- $\beta$-D-manno heptose-1,7-bisphosphate (HBP) bacterial metabolites (Gaudet et al., 2015), and metabolites derived from nutrients with the help of bacteria, namely vitamins, amino acids, metabolites that are ligand for aryl hydrocarbon receptor (AHR) (Jin et al., 2014; Natividad et al., 2018), polyamines (Hesterberg, Cleveland, \& Epling-Burnette, 2018), and short-chain fatty acids (Gill et al., 2018).

\section{INTESTINAL DYSBIOSIS}

Microbiome profiling in healthy people provides data on the microbiota in particular organs. Individual differences in the human microbiome are specific, functionally important, and personalized (Human Microbiome Project Consortium, 2012). It has been also noticed that Bacteroides prevail in people with small variety of Firmicutes (Human Microbiome Project Consortium, 2012).

Balance between organisms making up the intestinal ecosystem may be disrupted not only by taking broadspectrum antibiotics, but also by antiviral or antifungal drugs. Changes in human gut microbiota composition can be associated with commonly used non-antibiotic drugs, such as proton pump inhibitors (PPIs), nonsteroidal anti-inflammatory drugs (NSAIDs), atypical antipsychotics (AAPs), but also by antidiabetics - metformin (Maier et al., 2018). The modulation of the intestinal microflora composition is influenced by the variety in diet, long-lasting stress, and adverse environmental factors (among them bisphenol A) (Malaisé et al., 2017).

Imbalance between microorganisms naturally colonizing the host, and their disturbed functioning, is called dysbiosis. In macroorganisms inhabited by microorganisms, such a situation triggers the immune response, affects the host's metabolism, and can possibly contribute to the development of inflammatory diseases (Lee \& Kim, 2017; Miyoshi et al., 2017; Saltzman et al., 2018; Slingerland, Schwabkey et al., 2017; Zechner, 2017).

Owing to the fact that different groups of microorganisms are involved and interact with each other, several types of dysbiosis can be distinguished.

One example is the presence of pathobionts - symbiotic microorganisms that under normal circumstances do not affect the host's health and do not elicit an inflam- matory response. But under particular conditions (environmentally induced) they have the potential to cause dysregulated inflammation leading to a disease (Chow et al., 2011). Moreover, pathobionts are capable to expanding during episodes of inflammation and may exacerbate the disease process. For example Clostridium (C.) difficile, C. perfringens, Fusobacterium nucleatum or enterotoxic strain Bacteroidetes fragilis, occur in the healthy human gut microbiome (Maier et al., 2018), but in some cases are considered as pathological factors (Fukugaiti et al., 2015; Komiya et al., 2018; Purcell et al., 2017; Tajkarimi \& Wexler, 2017). Moreover, in the murine IBD (inflammatory bowel disease) model, it was shown that a pathobiont (Helicobacter billis) may synergize with commensal strains of bacterial microbiota and exacerbate pathology in this disease, which was demonstrated by the increase in TGF $\beta$ and proinflammatory cytokines (IL-1 $\beta$, IL-17A, IL-17F), secreted by the Th17 cells (Gomes-Neto et al., 2017). Nevertheless, as a result of gene mutation in bacterial type VI secretion system (T6SSs) or intestinal factors, such bacteria may cause infections and inflammatory states in mice (Chow \& Mazmanian, 2010; Maier et al., 2018). Another example of a pathobiont is Helicobacter (H.) hepaticus, which can be involved in inflammatory gut diseases through the induction of Th17 proinflammatory lymphocytes. A murine model-based research (Xu et al., 2018) demonstrated that inactivation of c-MAF transcription factor in Treg lymphocytes disturbed their differentiation and function, which was manifested by lower IL-10 levels. This, in turn, favored accumulation of the Th17 cells and increased inflammatory response to H. hepaticus (Xu et al., 2018).

Another contributor to dysbiosis is the loss of commensal bacteria, stemming from elimination of bacterial cells, or inhibition of their proliferation (Korem et al., 2015).

Dysbiosis is also characterized by lower diversity of bacterial species inhabiting particular places in the body. Diversity of commensal microorganisms is shaped from birth (Nagpal et al., 2017). What is more, it can be modulated by dietary habits (Cotillard et al., 2013), as well as obesity and related metabolic changes (Le Chatelier et al., 2013).

On the basis of a murine model, it has been demonstrated recently that the intestinal microbiota are also affected by the process of aging (Langille et al., 2014), which can contribute to systemic inflammatory states (inflammaging) (Kim et al., 2016; Fransen et al., 2017). The reported results suggest that 'old' intestinal microbiota transplanted to germ free (GF) mice increase the production of tumor necrosis factor $\alpha$ (TNF- $\alpha$ ), whose chronic secretion can exert adverse effects on metabolic processes and insulin resistance, and produce inflammatory changes in the arterial walls. Furthermore, 'aging' of the intestinal microflora was proved to be a far more important source of proinflammatory bacterial factors (including bacterial lipopolysaccharide, LPS) released to the blood circulation system, than the microbiota of young animals. It was also found that with age, Firmicutes outnumber Bacteroidetes (Kim et al., 2016; Fransen et al., 2017). A human population based study (Claesson et al., 2011) demonstrated that the intestinal microflora phylum predominating in aging individuals is Bacteroidetes. In younger adults, the more common phylum is Firmicutes, which may vary between individuals. Another study provided evidence for individual differences in the intestinal microflora between aging adults, depending on their health status. The composition of the intestinal microflora of people receiving long-term residential care 
correlates with elevated levels of inflammatory markers (serum IL-6, IL-8, C-reactive protein (CRP) and TNF- $\alpha$ ) and nutritional status (Claesson et al., 2012). The authors also reported that their analysis of fecal samples revealed differences in the levels of SCFAs, which was assessed on the basis of the frequency of the genes responsible for the production of these bacterial metabolites. The long-hospitalized patients had considerably fewer genes associated with the production of butyrate and acetate than their non-hospitalized counterparts. These data show that SCFAs may belong to important metabolites, having an impact on the health status (Claesson et al., 2012). Additionally, in a study conducted by Kato and others (Kato et al., 2017), it was found that changes in composition of the gut Bifidobacterium (B.) species in the human intestine are age-related and vary between life stages. With ageing, there is a decrease in B. breve and an increase in B. dentium (Kato et al., 2017). Recent research also indicates participation of a human gut microbiota in biological aging. The process of human aging is characterized as a progressive reduction in organ functions and a decrease in physical activity (Maffei et al., 2017). Clinically, the aging process manifests itself in many symptoms, including: anorexia and weight loss, sarcopenia, cognitive decline and low levels of activity - together these symptoms are indicative of occurrence of the frailty syndrome, which is related to the,,biological" and not the „chronological" age. Examination of faecal samples demonstrated that richness of microbial community correlates to frailty in aging people (Maffei et al., 2017).

It has not been clearly confirmed so far whether intestinal dysbiosis is a result or a cause of numerous immune (Ni et al., 2017; Nishida et al., 2018; Penders et al., 2007) and metabolic disorders (Org et al., 2017). Disturbance of the composition and functioning of the intestinal microflora accompany many inflammatory diseases, e.g. Crohn's disease, inflammatory bowel disease (IBD), irritable bowel syndrome (IBS), atherosclerosis, atopic dermatitis, psoriasis, asthma, multiple sclerosis and systemic lupus erythematosus, which has been reviewed in (Slingerland et al., 2017). A human population based study (in men aged 45-70) (Org et al., 2017) demonstrated a relationship between gut microbiota and serum levels of metabolites (fatty acids, amino acids, lipids, and glucose), which may be associated with metabolic disorders in the pre-diabetic state, the development of obesity, insulin resistance and cardiovascular disease in aging people.

In another human population based study, Maffaei and others (Maffaei et al., 2017) had suggest that the identified bacterial genera (Eggerthella, Coprobacillus and Lachn. Ruminococcus) may contribute to an increase in symptoms associated with frailty. Eggerthella is a common commensal occurring in the human intestine. Its increased relative abundance has been observed in aging people (Jackson et al., 2016), and in studies conducted with a mouse model where intestinal microflora changes in aging mice were accompanied by an increase in proinflammatory factor MCP-1 in serum (Conley et al., 2016). Influence of intestinal microflora on aging - especially on frailty and dementia, has been described in a systematic review that identified 47 original research papers - 31 animal models and 16 human based studies. This study demonstrated that perturbed animal gut microbiota is linked to e.g. neuroinflammation, or in the case of probiotic administration the microbiota might be improved and affect the weakening of inflammation (Ticinesi et al., 2018).

In turn, in research conducted by Biagi and others (Biagi et al., 2016) the effect of intestinal microbiota on longevity was analyzed. This study demonstrated the presence of a core microbiota, dominated by symbiotic bacterial taxa (Rumicoccocaceae, Lachnospiraceae and Bacteroideacea). Moreover, in semi-supercentenarians (aged 105-109) the microbial ecosystem is enriched in Akekermansia, Bifidobacterium and Christensenellaceae - health-associated bacteria, known to promote immunomodulation and metabolic homeostasis (Biagi et al., 2016). In addition, it is also indicated that SCFAs may play an important role in the aging process. As reviewed by Riaz Rajoka and others (Riaz Rajoka et al., 2018) there is a relationship between gut microbiota and aging related diseases. Moreover, the change in composition of the gut microbiota affects production of SCFAs (mainly butyrate) which have anti-inflammatory properties, and reduction in their level may increases inflammation in elderly people (Riaz Rajoka et al., 2018).

Aside from microorganism-associated molecular patterns (MAMPs) that are expressed by components of the resident microbiota, as well as pathogens recognized by pattern recognition receptors (PRR), the microbial metabolites also influence the host's intestinal microflora and immune system. In the process of anaerobic fermentation of exogenous components - such as dietary fiber and other indigested carbohydrates from food the products, i.e SCFAs, emerge that modulate the immune mechanisms and ensure immunity determined by the integrity of the mucous membrane. The intestinal mucosal barrier plays an essential role in separation of the inside of the body from the outside environment. This highly-specialized barrier composed of the mucous layer, epithelium, and lamina propria-populated by innate and adaptive immune cells - actively participates in homeostatic responses to microorganisms without causing inflammation. If, however, this barrier is broken, the mechanisms of innate and adaptive immune response induce microorganism combat and tissue repair (Maynard et al., 2012).

\section{SHORT-CHAIN FATTY ACIDS (SCFAs)}

Products of microbial activity, short-chain fatty acids (SCFAs) have one to six carbon atoms (C1-C6). They include acetate (C2), propionate (C3), and butyrate (C4), which are essential for intestinal homeostasis, since they maintain proper microbiome dynamics through inhibiting proliferation of some bacteria at a low $\mathrm{pH}$ environment (Tramontano et al., 2018). These acids affect immune reactions not only in the intestines, but also in distant tissues (Park et al., 2015; Milligan et al., 2017). Acetate emerges as a product of pyruvate conversion, either directly from acetyl-CoA or by the reductive acetyl-CoA or Wood-Ljungdahl pathway (Ragsdale \& Pierce, 2008). Propionate is synthesized via the succinate pathway. Additionally, it is produced by the acrylate pathway from lactate as a precursor, with simple sugars (pentoses and hexoses) as substrates in these reactions. Propionate is also synthetized via the propanediol pathway with deoxyhexoses (fucose and rhamnose) as substrates (Reichardt et al., 2014). Butyrate is formed by classical routes as a result of the reduction of acetoacetyl CoA to butyryl CoA, converted to butyrate by transbutyrylase and butyrate kinase (Pryde et al., 2002). Butyryl CoA may yield butyrate via butyryl-CoA transferase-acetate Co-A (Duncan et al., 2002; Vital et al., 2014) (Table 1). These acids are transported to intestinal epithelial cells via simple diffusion and active transport. C2 and C3 are absorbed by blood and distributed to other tissues and organs, whereas C4 is the source of energy and influences me- 
Table. 1 Biosynthesis of SCFAs in the intestine

\begin{tabular}{|c|c|c|c|}
\hline \multicolumn{4}{|c|}{ Biosynthesis of SCFAs in the intestine } \\
\hline SCFA & Biosynthesis & Microorganisms & References \\
\hline \multirow[b]{2}{*}{ acetate } & $\begin{array}{l}\text { from pyruvate in acetyl-CoA } \\
\text { pathway }\end{array}$ & $\begin{array}{l}\text { Akkermansia muciniphila, Bacteroides spp., Bifidobacterium } \\
\text { spp., Prevotella spp., } \\
\text { Ruminococcus spp. }\end{array}$ & \multirow[b]{2}{*}{ Koh et al., 2016} \\
\hline & $\begin{array}{l}\text { reductive acetyl-CoA pa- } \\
\text { thway (Wood-Ljungdahl } \\
\text { pathway) }\end{array}$ & $\begin{array}{l}\text { Blautia hydrogenotrophica, Clostridium spp., Streptococcus } \\
\text { spp. }\end{array}$ & \\
\hline \multirow{3}{*}{ propionate } & succinate pathway & $\begin{array}{l}\text { Bacteroidetes spp, Roseburia spp., Firmicutes, Roseburia inu- } \\
\text { linivorans, Ruminococus spp., Cllostridium spp., Clostridiales } \\
\text { bactrium, Eubacterium spp, Coprococcus spp., Dialister succi- } \\
\text { natiphilus, Phascolarctobaterium succinatutens, } \\
\text { Akkermansia muciniphila }\end{array}$ & \multirow{3}{*}{ Reichardt et al., 2014} \\
\hline & acrylate pathway & $\begin{array}{l}\text { Clostridium sp., Clostridiales bacterium, } \\
\text { Coproccus catus, Clostridium sp., }\end{array}$ & \\
\hline & propanediol pathway & $\begin{array}{l}\text { Roseburia insulinivorans, Ruminococus spp., Eubacterium halli, } \\
\text { Clostridium sp. }\end{array}$ & \\
\hline \multirow[t]{2}{*}{ butyrate } & $\begin{array}{l}\text { butyryl-CoA transferase:ace- } \\
\text { tate Co-A pathway }\end{array}$ & $\begin{array}{l}\text { Roseburia intestinalis, Eubacterium rectale, Roseburia in- } \\
\text { sulinivorans, Clostridiales bacterium, Anaerostripes hadrus, } \\
\text { Coprococcus spp, Clostridium symbiosum, Faecalibacterium } \\
\text { prasnitzii, }\end{array}$ & $\begin{array}{l}\text { Reichardt et al., } 2014 \\
\text { Vital et al., } 2014\end{array}$ \\
\hline & butyrate kinase pathway & Bacteroidetes spp., Coprococcus spp. & $\begin{array}{l}\text { Reichardt et al., } 2014 \\
\text { Vital et al., } 2014\end{array}$ \\
\hline
\end{tabular}

tabolism of intestinal epithelial cells (Pryde et al., 2002; Park et al., 2015). The levels of SCFAs in the intestines range from 20 to $140 \mathrm{mM}$, and depend on the intestinal microflora composition, absorption of SCFAs from the intestines, and the fiber content in the diet (Rooks \& Garrett, 2016).

\section{RECEPTORS FOR SHORT-CHAIN FATTY ACIDS}

Free fatty acids receptors (FFARs), belonging to the GPCR family, recognize SCFAs and take part in signal transmission. They are polypeptides consisting of seven transmembrane $\alpha$-helix domains (7 TMD). These domains consist of an extracellular $\mathrm{N}$ terminus with three extracellular loops (EL1, EL2, EL3), and an intracellular C terminus with three intracellular loops (IL1, IL2, IL3). SCFAs activate four different receptors located in the cell membranes. These include mammalian FFAR2 (also known as GPR43) and FFAR3 (also known as GPR41), hydroxycarboxylic acid receptor 2 (HCA2) (also called GPR109a), as well as other receptors belonging to the GPCR family: Olfr-87 in mice, and OR51E2 in humans (Bolognini et al., 2016; Pluznick, 2016; Ohira et al., 2017). GPR43 is mainly stimulated by acetic, propionic and butyric acids. However, acids that have the greatest potential to activate GPR41 are the propionic and butyric acids, and slightly less effective - the acetic and formic acids (Brown et al., 2003; Le Poul et al., 2003). Apart from niacin and ketone bodies, the butyric and $\beta$-hydroxybutyric acids are also ligands for GPR109a. Propionic and acetic acids are produced by bacterial microflora and are also activators for Olfr-87 (Pluznick et al., 2013). What is more, SCFAs (mainly C4 and C3) are believed to take part in the activation of the peroxisome proliferator-activated receptors $\gamma$ (PPAR $\gamma)$, stimulating synthesis of angiopoietin-like protein 4 (ANGPTL4) FIAF) in the large intestine adenocarcinoma cells, among others (Alex et al., 2013). ANGPTL4 is a newly recognized adipokine, regulating lipid metabolism. It may also be a joining factor between the gut microflora compo- sition and accumulation of the adipose tissue (Korek \& Krauss, 2015).

The main places of GPR43 expression are digestive tract epithelial cells and the immune system cells (Brown et al., 2003; D'Souza et al., 2017). This receptor can also be found on adipocytes in the adipose tissue (Brown et al., 2003). GPR41 is present on many cells of the human body, such as the large intestinal lamina propria cells, spleen cells, lymph nodes, bone marrow, adipocytes, polymorphonuclear leukocytes, and the peripheral nervous system cells (Brown et al., 2003; Le Poul et al., 2003). Both receptors are also found on cells in the distal tubules and kidney collecting ducts (Kobayashi et al., 2017). The presence of GPR109a has been confirmed in the large intestinal epithelium, and on immune system cells: macrophages, monocytes, dendritic cells, neutrophils, and adipocytes (Brown et al., 2003), but not on lymphocytes in the white and brown adipose tissue (Koh et al., 2016). Olfr-87 mainly occurs on neurons, enteroendocrine cells, epithelium of the large intestine, renal arteries, and smooth muscles of blood vessels (Table 2).

\section{SCFAs SIGNALING PATHWAY}

Ligand binding and activation of the receptor initiates the signal transmission cascade in the cell. In the case of GPCR signaling pathways, the first elements 'receiving' signal from the stimulated receptor are heterotrimeric $G$ proteins. In a resting state, $G$ proteins exist as complexes of $\alpha, \beta$ and $\gamma$ subunits. Activity of $G$ proteins is regulated by the guanosine diphosphate (GDP)-bound $\alpha$-subunit. $\mathrm{G} \alpha$ subunits include four protein subclasses: $\mathrm{G} \alpha_{(\mathrm{s})}$, $G \alpha_{(\mathrm{i} / \mathrm{o})}, G \alpha_{(\mathrm{q} / 11)}$ and $G \alpha_{(12 / 13)}$, each of them activating a specific signaling pathway. Upon ligand binding to the receptor, GDP dissociates from $\mathrm{G} \alpha$, which in turn binds to GTP. The G $\alpha$-GTP complex dissociates from the $\beta \gamma$ heterodimer. Next, these two components (G $\alpha-G T P$ and $\beta \gamma)$ are involved in transmitting the signal inside the cell to an adjacent target molecule (an ion channel or adenylyl cyclase) (Keshelava et al., 2018). Transduction of 
Table. 2 Receptors for short-chain fatty acids

\begin{tabular}{|c|c|c|c|}
\hline \multicolumn{4}{|c|}{ Receptors for short-chain fatty acids } \\
\hline Receptor & Location & SCFA & References \\
\hline $\begin{array}{l}\text { FFAR2 (Free fatty acid } \\
\text { receptor 2) } \\
\text { (GPR43) }\end{array}$ & $\begin{array}{l}\text { digestive tract epithelial cells, immune system } \\
\text { cells, adipocytes in adipose tissue }\end{array}$ & $\begin{array}{l}\text { acetate, propionate, } \\
\text { butyrate }\end{array}$ & $\begin{array}{l}\text { Brown et al., 2003; D'Souza } \\
\text { et al., } 2017\end{array}$ \\
\hline $\begin{array}{l}\text { FFAR3 (Free fatty acid } \\
\text { receptor 3) } \\
\text { (GPR41) }\end{array}$ & $\begin{array}{l}\text { large intestine lamina propria cells, spleen cells, } \\
\text { lymph nodes, bone marrow, adipocytes, polymor- } \\
\text { phonuclear leukocytes, and in peripheral nervous } \\
\text { system cells, distal tubules and kidney collecting } \\
\text { ducts }\end{array}$ & $\begin{array}{l}\text { acetate, propionate, } \\
\text { butyrate }\end{array}$ & $\begin{array}{l}\text { Brown et al., 2003; Kobay- } \\
\text { ashi et al., } 2017\end{array}$ \\
\hline $\begin{array}{l}\text { GPR109a } \\
\text { (HCA2, hydroxycarboxy- } \\
\text { lic acid receptor 2) }\end{array}$ & $\begin{array}{l}\text { large intestinal epithelium, macrophages, mono- } \\
\text { cytes, dendritic cells, neutrophils, and adipocytes }\end{array}$ & $\begin{array}{l}\text { niacin, ketone bodies, } \\
\beta \text {-hydroxybutyric acids, } \\
\text { butyrate }\end{array}$ & Brown et al., 2003 \\
\hline $\begin{array}{l}\text { Olfr-87 (murine) } \\
\text { OR51E2 (human) }\end{array}$ & $\begin{array}{l}\text { neurons, enteroendocrine cells, the epithelium of } \\
\text { the large intestine, renal arteries, smooth muscles } \\
\text { of blood vessels }\end{array}$ & acetate, propionate, & $\begin{array}{l}\text { Bolognini et al., 2015; Plu- } \\
\text { znick et al., 2013; Pluznick } \\
\text { et al., 2016; Ohira et al., } \\
2017\end{array}$ \\
\hline PPARY & large intestine adenocarcinoma cells & propionate, butyrate & Alex et al., 2013 \\
\hline
\end{tabular}

a signal from stimulated FFAR2 (GPR43) and FFAR3 (GPR41) takes place via proteins from the heterotrimeric G-protein family $-G_{\mathrm{i} / \mathrm{o}}$ and $\mathrm{G}_{\mathrm{q} / 11}$ (Le Poul et al., 2003; Kobayashi et al., 2017; Milligan et al., 2017) (Fig. 1).
Signaling via FFARs plays an important part in modulation of the immune and inflammatory response. A study with mice had demonstrated that abnormalities in the expression of these receptors contribute to the devel-

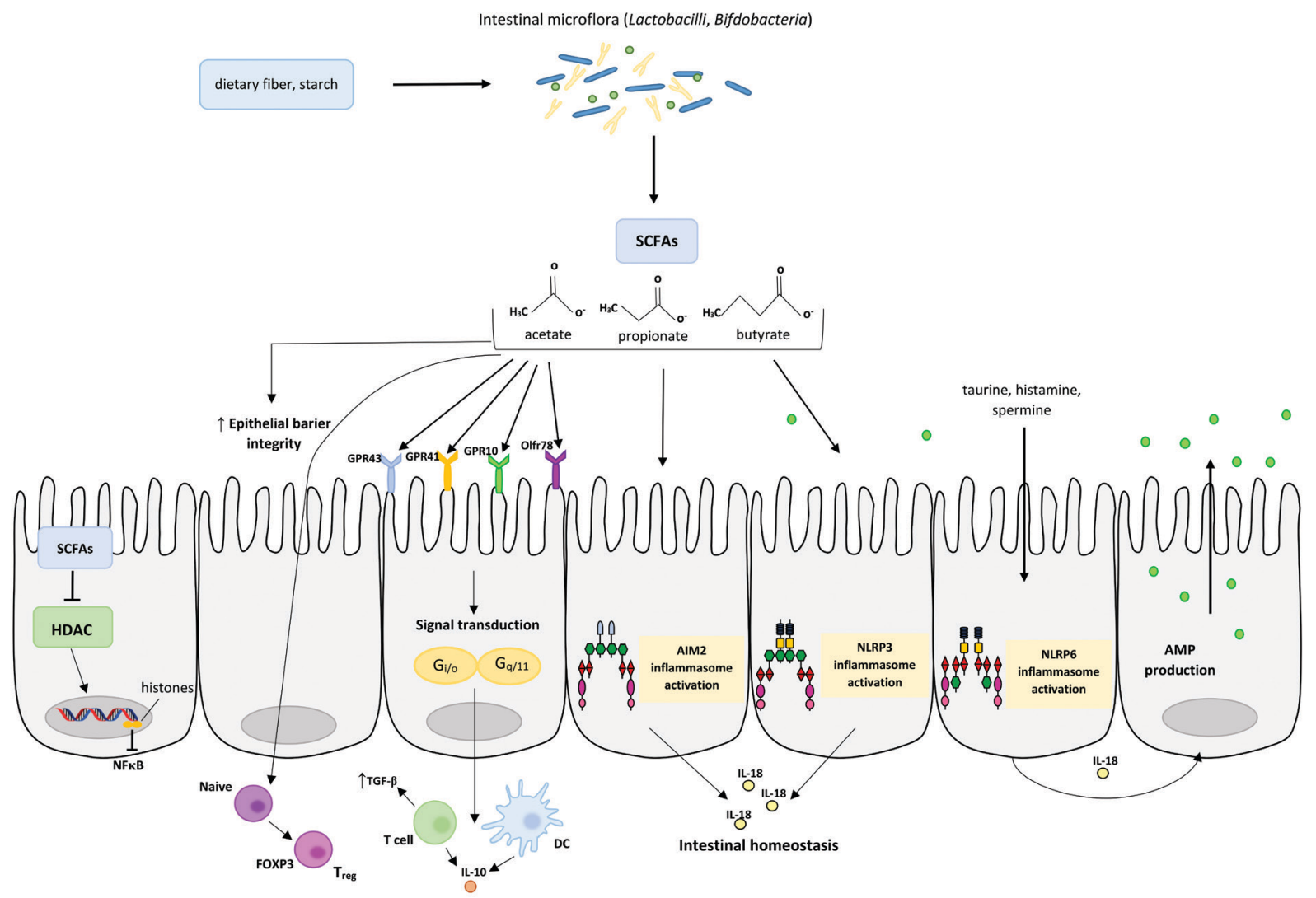

Figure. 1 Immune cell functions regulated by short-chain fatty acids (SCFAs).

SCFAs - butyrate, propionate and acetate are produced by intestinal microflora in fermentation of undigested dietary fiber or starch and influence the host immune system development and function. SCFAs activate G protein-coupled receptors (GPCRs), such as GPR41, GPR43, GPR109a and Olfr78. SCFAs influence the histone deacetylase (HDAC) activity which affects inhibition of nuclear factors, e.g. nuclear factor-KB (NF-KB). Moreover, SCFAs activate AIM2 and NLRP3 inflammasomes which then affects production of interleukin-18 (IL-18) and enhanced epithelial barrier function, while activation of NLRP6 inflammasome and secretion of IL-18 regulates the production of intestinal antimicrobial peptides (AMPs). SCFAs also regulate the development of immune cells, increase the number of Treg cells and affects the T lymphocyte and dendritic cell (DC) functions. 
opment of diabetes, obesity, colitis, colon cancer, atherosclerosis, as well as hypertension and respiratory diseases (especially asthma). What is more, in vitro examination in human monocytes revealed that FFAR2 and FFAR3 interact to form a heteromer that may play a part in the activation of a signaling pathway with p38 protein, and this additionally contributes to immune diseases (Ang et al., 2018). Another known function of FFARs stimulated by SCFAs (mainly propionic acid) is their modulatory role in the activity of the sympathetic nervous system which helps to maintain homeostasis in the organism, which has been confirmed with a murine model (Kimura et al., 2011). As a result of GPR41 stimulation on adipocytes in the adipose tissue, C3 contributes to secretion of leptin in cultured adipocytes and in an animal model based study (Xiong et al., 2004). The murine Olfr78 receptor, on the other hand, activated by propionate, is involved in renin secretion and in regulation of blood pressure (Pluznick et al., 2013).

\section{SHORT-CHAIN FATTY ACIDS, POST-TRANSLATIONAL MODIFICATIONS AND THE IMMUNE RESPONSE}

SCFAs inhibit histone deacetylases (HDACs), which are involved in regulation of expression of genes promoting pathogenesis in many diseases (Grabarska et al., 2013). Overexpression of HDACs results in the reduction of histone acetylation, thus leading to gene silencing during transcription (Grabarska et al., 2013). As an example, SCFAs may act on mononuclear blood cells and neutrophils through inhibition of HDAC, which consequently reduces production of the proinflammatory tumor necrosis factor (TNF) by these cells and leads to inactivation of a transcription factor - nuclear factor

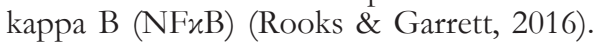

Enzyme-controlled histone post-translational modifications (HPTMs) are a key element of gene expression regulation (Fig. 1). The best elucidated HPTM mechanism is histone acetylation, controlled by acetyltransferases (HATs) and deacetylases (HDACs) (Fellows et al., 2018). In the process of histone deacetylation, removal of the acetyl group from $\varepsilon N$-acetyl-lysine results in a more effective DNA coiling around histones. Increased acetylation and hyperacetylation of chromatin determines its transcriptional activity, which is essential for gene expression. An impact of HDAC inhibition on the functioning of immune cells has been confirmed for murine Treg lymphocytes (Tao et al., 2007). Tao and others (Tao et al., 2007) reported that the HDAC inhibitor (HDACi) increases gene expression of Foxp3 in Treg cells, and improves their suppressive properties.

It has been also found in a murine model study that the acetylation of Foxp3 promotes its binding to the Il2 promoter region, which results in the inhibition of endogenous IL-2 secretion. IL-2, on the other hand, is involved in the conversion of Foxp $3^{+}$Treg cells to colitis-related Foxp3 $3^{+} \mathrm{IFN}-\gamma^{+}$T cells (Feng et al., 2011). Another example is the impact of HDAC inhibition on maturation, differentiation, and immunogenicity of DCs (Chauvistré et al., 2014; Nencioni et al., 2007). SCFAs, especially butyric acid, have been confirmed to inhibit the HDAC activity (Chang et al., 2014; Waldecker et al., 2008). The SCFA produced by commensal bacteria-n-butyrate - as an inhibitor of HDAC can modulate the function of macrophages present in the lamina propria of mice gut (Chang et al., 2014). A study on a mouse model provided evidence that in the mechanism dependent on HDAC inhibition, the expression of genes encoding proinflammatory mediators (nitic oxide synthase - Nos2, Il6, IL12a, and IL12b) is reduced. Lower levels of NO, IL-6, and IL-12 produced by macrophages can help to provide and maintain the immune homeostasis, and decrease inflammation in the colon (Chang et al., 2014). Currently, we can also identify other post-translational modifications, such as crotonylation, butyrylation, and hydroxybutylation. SCFAs, which are essential for normal intestinal physiology, are an important source of energy for intestinal epithelial cells and a vital factor joining the cell metabolism to translational regulation. The most recent data indicate that SCFAs are also crucial for the process of crotonylation (Fellows et al., 2018), which is a stronger activator of transcription than acetylation, and involves joining crotonyl-CoA to histone lysine residues (Sabari et al., 2015). Fellows and others (Fellows et al., 2018) analyzed crotonylation in the murine tissues of colon, brain, liver, spleen, and kidneys. This process was the most intense in the intestine, and very intense in the brain. It was also demonstrated that modification of histones depended on SCFAs, mainly butyric acid (C4), whose level was highest in the intestine, but also high in the blood serum, which explains why crotonylation is observed in distant tissues (for example, in the brain), and not only locally in the intestines. The available report (Fellows et al., 2018) suggests that SCFAs (mainly C4) increase histone crotonylation in intestinal epithelial cells through inhibition of the decrotonylase activity of HDACs. Another very important factor contributing to the process of crotonylation is the composition of the intestinal microflora that can be modified by the use of antibiotics. As shown by Fellows and others (Fellows et al., 2018), the loss of the commensal intestinal microflora substantially contributes to a decline in SCFA levels, both in the intestinal tissues and in the serum. On the other hand, SCFA deficiency leads to an increased expression of HDAC2 in the intestine and loss of histone crotonylation. Expression of HDAC2 leads to pathologies, such as tumorigenesis in the large intestine human tissue which has been confirmed by Ashktorab and others (Ashktorab et al., 2009). The latest research, but conducted with a murine model of intestinal tumorigenesis (Ravillah et al., 2014), confirmed that inhibition of HDAC2 influences inhibition of tumorigenesis through decreased expression of $\mathrm{G} 2 / \mathrm{M}$ phase cell cycle regulatory proteins, $\mathrm{Bcl}-2$ protein and upregulated expression of p53 protein in the mouse colon tissue.

\section{IMMUNE RESPONSE MODULATED BY SHORT-CHAIN FATTY ACIDS}

SCFAs exert an impact on cells by three different mechanisms. The first of them is the activation of cellular receptors, resulting in cell proliferation or differentiation. Secondly, after penetrating into cells, SCFAs affect their metabolism. Thirdly, SCFAs act as HDAC inhibitors (Astakhova et al., 2016). In a human cell line based study, Astakhova and others (Astakhova et al., 2016) demonstrated how SCFAs influenced signaling pathways in cancerous epithelial and lymphoid cells (B-cell lymphoma, BL), which were additionally Epstein-Barr virus (EBV) positive. The SCFA that they focused on was $\mathrm{N}$-acetyl butyric acid, which triggered proinflammatory IL-8 and IL-6 expression and increased NFxB activity in the cancerous epithelial and lymphoid cells. Moreover, SCFAs induced early stages of the lytic cycle of the Epstein-Barr virus (EBV), which was confirmed by expression of viral proteins involved at this stage of a viral 
cycle. Butyric acid also had an effect on the induction of apoptosis in lymphoid cancerous cells. Another parameter assessed by Astakhova and others (Astakhova et al., 2016) was inhibition of cancerous cells with high migration potential. The authors found that even very low levels of N-acetyl butyric acid inhibited migration of these cells. They demonstrated that transport proteins MCT1 (monocarboxylate transporter 1, also known as solute carrier family 16 member 1) and MCT4 (monocarboxylate transporter 4, also known as solute carrier family 16 member 3) were essential for the SCFA activity and penetration into cells. These data show that the presence of SCFAs and their influence on transporter cells enable elimination of cancerous and EBV-infected cells (Astakhova et al., 2016).

SCFAs promote differentiation of $\mathrm{T}$ lymphocytes into effector $\mathrm{T}$ cells (Te) and regulatory $\mathrm{T}$ cells (Treg) via HDAC inhibition but it is independent of GPR41 or GPR43. The mTOR-S6K kinase pathway is essential for differentiation of the $T$ lymphocytes (Park et al., 2015). Inhibition of HDACs in T lymphocytes by SCFAs (C2 and C3) can enhance phosphorylation of the ribosomal protein $\mathrm{S} 6(\mathrm{rS} 6)$, which is the major target of the mTOR pathway. It has an impact on expression of IL-10, IL-17 and IFN $\gamma$ - the key effector and regulatory cytokines in $\mathrm{T}$ cells. Based on in vitro research, it has been demonstrated that $\mathrm{C} 2$ can regulate $\mathrm{T}$ cell populations, which is modulated by immunological context and cytokine milieu. The population of $\mathrm{T}$ lymphocytes secreting IL10 were increased by SCFA in the steady condition in vivo, whereas in an active immune response, only $\mathrm{C} 2$ increased the number of the effector $\mathrm{T}$ cells (Park et al., 2015). This phenomenon seems to be important because secretion of IL-10 by Te lymphocytes determines their anti-inflammatory properties, which is critical in weakening the immune response in inflammatory diseases of various organs. These research also suggested that propionate in the intestine may promote the differentiation of Treg cells producing IL-10 and expressing the Foxp3 gene. What is more, both C2 and C3 (in vitro) promote differentiation of naive $\mathrm{T}$ lymphocytes into $\mathrm{T}$ helper 17 (Th17) cells, and in the presence of IL-12 they lead to induction of Th1 lymphocytes. This, however, depends on the dose and the level of the acid. Th1 and Th17 lymphocytes are involved in the immune response to pathogens, and mediate the inflammatory response (Park et al., 2015).

\section{SCFAs AND THE URINARY TRACT}

A favorable effect of SCFAs is well known. There are data, however, indicating that their permanently elevated levels contribute to inflammatory states, which was demonstrated with the example of the murine urinary tract model (Park et al., 2016). Long-term administration of SCFAs (especially C2) was found to cause their substantial increase in the intestinal tissue and blood, with the highest level observed in the renal tissues. Immunohistochemical analysis confirmed that mice with chronic renal disease (CRD) provided with $\mathrm{C} 2$, had elevated tissue levels of $\mathrm{CD}^{+}{ }^{+} \mathrm{T}$ and $\mathrm{CD} 11 \mathrm{c}^{+}$lymphocytes. An increase was also observed in the levels of Th1 and Th17 effector lymphocytes, as well as $\mathrm{IL}_{10}{ }^{+}$and Foxp $3^{+}$ $T$ cells. Additionally, in the tissues of the animals with CRD, the researchers observed a considerably higher expression of mRNA for IL-6, IL-17, IFN $\gamma$, CCL2, CCL5, CCL17, as well as for IL-10 and TGF $3-1$. The results reported by Park and others (Park et al., 2016) suggest that irrespective of the presence of GPR41 and GPR43, as a result of activation of the mTOR signaling pathway, SCFAs promote differentiation of $\mathrm{T}$ lymphocytes into Th1 and Th17, which seems to be critical for the occurrence of not severe but chronic inflammatory states in the CRD pathogenesis. A long-lasting increase in SCFA levels in the body is a consequence of dysbiosis. Through absorption of SCFAs into the blood circulation system and activation of signaling pathways in the immune system cells, such a state induces chronic inflammation which can lead to tissue damage in various organs (kidneys, for example) (Park et al., 2016). In spite of this, favorable effects of SCFAs (mainly the acetic and butyric acids) have been demonstrated in human population based studies when restraining the oxidative stress and inflammatory response in renal glomerular mesangial cells (GMC). Aside from a decrease in proliferation of GMC, as well as substantial inhibition of reactive oxygen species (ROS) and malondialdehyd (MDA), increased levels of an antioxidative enzyme - superoxide dismutase (SOD) - were observed. What is more, GMC stimulated by high levels of glucose and bacterial lipopolysaccharides (LPS) in the presence of SCFAs, secrete a substantially lower amount of IL-1 $\beta$ proinflammatory cytokine and leukocyte chemotactic factor, called CCL2 chemokine or monocyte chemoattractant protein (MCP-1) (Huang et al., 2017). This suggests that maintaining normal levels of SCFAs and identification of signaling pathways in which SCFAs are involved, can be essential for reducing inflammation in the renal diseases. Research on SCFAs as factors potentially reducing inflammatory states and fibrosis in renal tissues was also conducted by Kobayashi and others (Kobayashi et al., 2017). They noticed that propionic acid in the human renal cortical epithelial cells (HRCE) decreases MCP-1 expression dependent on TNF- $\alpha$. This mechanism is determined by lower phosphorylation of the p38 protein and the c-Jun $\mathrm{N}$-terminal kinase (JNK) via the pathway dependent on GPR41 and GPR43, which in this case joins mainly with the $G \beta / \gamma$ proteins (Kobayashi et al., 2017).

\section{SCFAs AND THE CENTRAL NERVOUS AND RESPIRATORY SYSTEMS}

Dysregulation of intestinal microbiota composition, and thus its metabolites, can also affect autoimmune reactions, including those in the central nervous system (CNS). Moser and others (Moser et al., 2017) analyzed patients with the clinically isolated syndrome (CIS) and patients with the early phase of multiple sclerosis (MS). The term CIS refers to a first episode of neurologic symptom onset of potential multiple sclerosis (MS). It is caused by inflammation and loss of myelin covering the neurons (demyelination) in the CNS (Efendi, 2016). Moser and others (Moser et al., 2017) noticed that the levels of acetic and butyric acids in feces samples of the CIS and MS patients were significantly lower than in the control group. Furthermore, the patients with demyelinating disease had considerably fewer $\mathrm{CD}_{103^{+}}$tolerogenic dendritic cells (DC) and CD4+25+127- 'Treg lymphocytes in the descending colon bioptates than the control group. These data suggest a relationship between a decline in the SCFA levels and deficiency of DCs and Treg cells stimulated by these acids, and pathological symptoms in MS patients (Moser et al., 2017).

The influence of intestinal dysbiosis and disturbed SCFA levels have been also confirmed as factors exacerbating inflammation in allergies of the respiratory 
system (lungs) (Cait et al., 2017). Research with a murine model has provided evidence that antibiotic (vancomycin) treatment reduces both, the number and variety of intestinal bacteria species, producing SCFAs. It is worth mentioning that mice receiving vancomycin exhibited an enhanced allergic reaction, confirmed by an increase in eosinophils in the airways, and elevated serum IgE levels. An increased immune response was inhibited in animals by butyric acid (C4) supplementation. In the same study, in vitro examination of cells taken from mice receiving antibiotics revealed that $\mathrm{C} 4$ decreases population of the $\mathrm{CD}^{+}{ }^{+} \mathrm{T}$ lymphocytes in which expression of IL-4 is observed. IL-4 is mainly produced by stimulated Th2 lymphocytes, and takes part in the change of antibody classes from IgM through $\operatorname{IgG}$ to $\operatorname{IgE}$. This suggests that there are relationships between the activation of Th2 cells, increased expression of IL-4, elevated serum IgE levels, and an inflammatory allergic reaction. Also, Cait and others (Cait et al., 2017) analyzed the anti-inflammatory influence of SCFAs on murine DC cells. Genetic analysis had shown that DC cells activated by contact with an allergen, but subjected to C4 activity, were less likely to stimulate $\mathrm{T}$ lymphocytes and their chemotactic properties were also weaker. These data imply that intestinal dysbiosis increases an allergic reaction in lungs by stimulating inflammatory response mechanisms in which T lymphocytes and DC cells are involved. Nastasi and others (Nastasi et al., 2015), who performed in vitro research to assess modulatory influence of SCFAs on the function of human monocyte-derived dendritic cells isolated from peripheral blood, demonstrated that GPR41 and GPR109A expression was like in the primary human $\mathrm{CD}_{1} \mathrm{c}^{+}$and $\mathrm{CD} 141^{+} \mathrm{DC}$ cells. In the same study, they also found that SCFAs that play the most important part in modulation of the function of mature dendritic cells are the propionic and butyric acids, reducing secretion of proinflammatory chemokines (among them, CCL3, $-4,-5$ and CXCL9, -10, -11 , but not CCL2, -11, and CXCL5). Both, C3 and C4 substantially reduced expression of IL-6 and IL12B-proinflammatory cytokines induced by bacterial LPS. The results of that study had clearly shown that propionic and butyric acids are those SCFAs that have the greatest immunomodulatory and direct influence on mature dendritic cells, which was manifested as inhibition of gene expression for selected cytokines and chemokines (Nastasi et al., 2015).

\section{SCFAs AND A DISTAL EFFECT - AN IMMUNE REACTION IN THE EYE}

Distant effects of SCFAs were demonstrated with the example of experimental autoimmune uveitis (EAU) in a murine model by Nakamura and others (Nakamura et al., 2017). The authors had confirmed a decreased length of the muscular layer of the small intestine and intestinal crypts in immunized mice, but this morphological change was significant during the beginning of uveitis. In propionate treated EAU mice the depth of intestinal crypts and villi length was increased. Moreover, oral administration of SCFAs changed the frequency of Treg cells in the cecal and colonic lamina propria lymphocytes (LPL), cervical lymph nodes (CLN), mesenteric lymph nodes and spleen, depending on time after administration SCFAs. Among others, SCFA supplementation given to the animals had alleviated the eye inflammation by induction of Treg cells, both in the intestines and the distant tissues and lymphatic organs. The researchers had noticed that administration of SCFAs abates migration of Th1 lymphocytes from the intestines to the spleen (Nakamura et al., 2017). Additionally, the connection between the intestinal homeostasis and uveitis may explains why the latter accompanies the autoimmune inflammatory diseases $(\mathrm{Na}-$ kamura et al., 2017).

\section{SCFAs AND THE IMMUNE REACTION IN OBESITY}

The metabolism of SCFAs is also a factor contributing to obesity. There are considerable differences in the microflora composition between slim, overweight, and obese people. Overweight and obese individuals have more Bacteroidetes mediating the production of propionic acid, which after absorption and distribution to the liver can become a substrate in the processes of gluconeogenesis or liponeogenesis. Obese people have noticeably higher C3 levels than slim ones (from $84.6 \mathrm{mmol} / 1$ to $103.87 \mathrm{mmol} / \mathrm{l}$ ) (Schwiertz et al., 2010). There are also data indicating that both, too high and too low SCFA levels can lead to obesity and other symptoms of the metabolic syndrome. A murine model research provided evidence that a long-term increase in C2 levels results in insulin resistance and elevated levels of triglycerides in the plasma, liver, and muscles (Perry et al., 2016). Excessive adipose tissue, progressive obesity, and the loss of metabolic homeostasis are the causes of inflammatory states. The main metabolic organ regulating energy balance is white adipose tissue (WAT) composed of adipocytes and stromal tissue which contains immunological cells. Immune system of the adipose tissue consists of M2 macrophages (Mf), type 2 innate lymphoid cells (ILC2), invariant natural killer T (iNKT) cells, as well as Th2 and Treg lymphocytes. Macrophages are cells that contribute to an inflammatory response associated with adipose tissue and stronger insulin resistance. Based on their experimental murine model, Nakajima and others (Nakajima et al., 2017) analyzed the impact exerted by SCFAs on the activation of GPR43 in the adipose tissue macrophages. What is interesting, the activated receptor fulfills different functions in the M1-type and M2-type macrophages. In the GPR43-dependent mechanism, TNF $\alpha$ expression is observed in M2 macrophages, but not in M1 macrophages. It shows that in the state of equilibrium in the adipose tissue, GPR43 regulates the SCFA-dependent immune response. $\mathrm{TNF} \alpha$, secreted by anti-inflammatory Mf with M2 phenotype, may contribute to suppression of adipose tissue accumulation by lowering the expression of glucose transporter isoform 4 (GLUT4) in the adipose tissue (Nakajima et al., 2017). Similar evidence for the role of SCFA-stimulated GPR43 and GPR41 in prevention of gaining weight and inhibition of obesity-related chronic inflammatory states was reported by $\mathrm{Lu}$ and others (Lu et al., 2016) in a murine model study. The authors also noticed a relationship between stimulated receptors and the activation of the processes of cellular metabolism - adipogenesis and oxidation. It should be emphasized that obese animals had elevated levels of proinflammatory IL-6, IL1 $\beta$, and MCP-1, which were substantially reduced by means of SCFA supplementation (Lu et al., 2016). Additionally, abnormal intestinal microflora was proved to increase the levels of SCFAs in feces and IL-6 in serum, which has an impact on lipid metabolism and the occurrence of subclinical metabolic changes in people (Rodríguez-Carrio et al., 2017). 


\section{DYSBIOSIS, SHORT-CHAIN FATTY ACIDS AND INFLAMMASOMES}

Effects of SCFAs are locally observed in the intestines. Recent data shows that SCFAs are bacterial metabolites indirectly involved in the activation of inflammasomes (Fig. 1). Inflammasomes are known as multiprotein cellular complex composed of a NOD-like receptor protein, the adaptor protein ASC and pro-caspase-1. Induction of this cellular complex leads to initiation of asignaling cascade in which activated caspase-1 contributes to secretion of interleukin IL-1 $\beta$ and IL-18 (Broz \& Dixit, 2016). IL-1 $\beta$ belongs to the IL-1 interleukin subfamily, its role in intestinal immunity has been reviewed by (Manzanillo et al., 2015). In intestinal immunity, IL-1 $\beta$ may have both, a protective and pathogenic function. Murine model studies demonstrated that genetic deletion of IL-1 $\beta$ retards the recovery of a gut epithelium. Moreover, IL-1 $\beta$ can modulate expression of other cytokines i.e. IL-22 in Th17 and Th22 cells. What is more, IL-1 $\beta$ may affect Treg cell differentiation and contribute to inflammatory state by inducing the Th17 cell differentiation. In synergy with $\mathrm{TNF}-\alpha$, IL-1 $\beta$ may play a role as an enhancer of epithelial tissue damage (Manzanillo et al., 2015). In a human pneumocystis cell line (THP-1 cells) (Ohira et al., 2012) investigated the effect of SCFA - butyrate, on expression of IL-1 $\beta$. Their study suggests that butyrate (in LPS stimulated THP-1 cells) enhances IL-1 $\beta$ production by activating caspase-1 via reactive oxygen species, as well as phosphorylation of the MAP kinase pathways and $G$ protein mediated pathways (Ohira et al., 2012). These data indicate that butyrate may play an important role in elevation of the inflammatory state. IL-18 is believed to be a cytokine that takes part in maintaining homeostasis and integrity, as well as the reconstruction of the intestinal epithelium. As shown with a murine model, a high-fiber diet, and thus increased SCFA production by intestinal bacteria, causes enhanced activation of the NLRP3 inflammasome in intestinal epithelial cells, as manifested by an increase in the IL-18 levels. Signaling mechanisms of inflammasome activation involve GPR43 and GPR109A, which cause hyperpolarization and an increased inflow of $\mathrm{Ca}^{2+}$ ions (Macia et al., 2015). Aside from fiber metabolites, a factor that activates inflammasome in the intestines is the bacterial flora whose composition and diversity depends on the type and intake of dietary fiber. In the study of Macia and others (Macia et al., 2015), the microflora isolated from mice consuming a greater amount of dietary fiber substantially increased the release of the active form of caspase-1 which clearly indicates enhanced induction of the inflammasome. Also, Levy and others (Levy et al., 2015) carried out research on the role of the intestinal microflora in inflammasome-related mechanisms, based om the murine model. They found that certain substances, such as taurine, histamine, and spermine, indirectly regulate production of intestinal antimicrobial peptides (AMPs) (intelectin 1 (ITLN1), resistin-like molecule $\beta$ (RELM $\beta$ ), angiogenin) through stimulation of NLRP6 inflammasomes and secretion of IL-18. Distortion of AMP balance by inflammasome deficiency drives dysbiosis development. Commensal bacteria take part in transcription of inflammasome components, and probably induce inflammasome formation, thus affecting IL-18 secretion. The authors also informed that the NLRP6/ IL-18/AMP signaling pathway ensures normal bacterial composition both, at the level of alpha- and beta-diversity (Levy et al., 2015). Nevertheless, Mamantopoulos and others (Mamantopoulos et al., 2017), had denied the
NLRP6 inflammasome to participate in the modulation of the gut microflora composition in a mice based study. Also, the AIM2 inflammasome, regulating the IL-18/ IL-22BP/IL-22 signaling pathway, promotes the maintenance of intestinal homeostasis and decrease in dysbiosis which has been confirmed with a murine model. In response to bacterial DNA, an active AIM2 inflammasome mediates IL-18 secretion, reducing IL22BP (IL-22 binding protein) expression, and thus leading to an increased activity of IL-22 in the intestine. Under such conditions, normal secretion of AMPs (such as REG3 $\beta$ and REG3 $\gamma$ ) occurs to control the composition of the intestinal microbiota, and to prevent dysbiosis. In the contrast, loss of AIM2 signaling predisposes to intestinal inflammation associated with abnormal functioning of the intestinal microflora. This is because reduced secretion of IL-18 boosts expression of IL-22BP, and decreases secretion of IL-22 and AMPs. During intestinal inflammation, on the other hand, elevated IL-18 levels reduce IL22BP expression via the IL-22 pathway, and thus activate STAT3 signaling pathways which increase the levels of REG3 $\beta$ and REG3 $\gamma$. Increased AMP production re-stimulates STAT3 based on a positive feedback loop, which in turn affects cell proliferation (Ratsimandresy et al., 2017). Furthermore, inflammasomes and SCFAs contribute to changes in the arterial wall structure in atherosclerosis. A murine model study (Yuan et al., 2018) demonstrated different effects of various SCFAs on activation of the NLRP3 inflammasome. It had shown that butyric acid can inhibit $\mathrm{O}_{2}^{--}$and the NLRP3 inflammasome formation and thus reduce the inflammatory response, preventing one of the causes of atherosclerosis-neointima (Yuan et al., 2018).

\section{CONCLUDING REMARKS}

Currently, many studies are being conducted to assess the contribution of intestinal microflora metabolites to the organism's homeostasis. The vast majority of them concern the influence that SCFAs exert not only on the intestinal environment, but also on distant tissues and organs. Increasingly, SCFAs are believed to play an immunomodulatory role, but nonetheless the mechanisms of their activity require further investigation. They seem to be essential for the differentiation of $\mathrm{T}$ lymphocytes, the reduced secretion of some inflammatory cytokines, and indirect inflammasome activation. Signal sending mechanisms from stimulated FFAR receptors, for which SCFAs are ligands, are also important. At present, both, the signaling pathways and receptors, are the new therapeutic targets in many inflammatory dysbiosis-related diseases. More in-depth SCFA analysis with regard to particular diseases would certainly help us understand their etiology and pathogenesis.

\section{REFERENCES}

Alex S, Lange K, Amolo T, Grinstead JS, Haakonsson AK, Szalowska E, Kersten S (2013) Short-chain fatty acids stimulate angiopoietinlike 4 synthesis in human colon adenocarcinoma cells by activating peroxisome proliferator-activated receptor. Mol CellBiol 33: 13031316. https://doi.org/10.1128/MCB.00858-12

Ang Z, Xiong D, Wu M, Ding J L (2018) FFAR2-FFAR3 receptor heteromerization modulates short-chain fatty acid sensing. FASEB J 32: 289-303. https://doi.org/10.1096/fj.201700252RR

Ashktorab H, Belgrave K, Hosseinkhah F, Brim H, Nouraie M, Takkikto M, Hewitt S, Lee EL, Dashwood RH, Smoot D (2009) Global histone h4 acetylation and HDAC2 expressionin colon adenoma and carcinoma. Dig Dis Sci 54: 2109-2117. https://doi.org/10.1007/ s10620-008-0601-7 
Astakhova L, Ngara M, Babich O, Prosekov A, Asyakina L, Dyshlyuk L, Matskova L (2016) Short chain fatty acids (SCFA) reprogram gene expression in human malignant epithelial and lymphoid cells. PLoS One 11: e0154102. https://doi.org/10.1371/journal. pone. 0154102

Biagi E, Franceschi C, Rampelli S, Severgnini M, Ostan R, Turroni S, Consolandi C, Quercia S, Scurti M, Monti D, Capri M, Brigidi P,Candela M (2016) Gut microbiota and extreme longevity. Curr Biol 26: 1480-1485. https://doi.org/10.1016/j.cub.2016.04.016

Bolognini D, Tobin AB, Milligan G, Moss CE (2016) The pharmacology and function of receptors for short-chain fatty acids. Mol Pharmacol 89: 388-398. https://doi.org/10.1124/mol.115.102301

Brown AJ, Goldsworthy SM, Barnes AA, Eilert MM, Tcheang L, Daniels D, Dowell SJ (2003) The orphan G protein-coupled receptors GPR41 and GPR43 are activated by propionate and other short chain carboxylic acids. J Biol Chem 278: 11312-11319. https://doi. org/10.1074/jbc.M211609200

Broz P, Dixit VM (2016) Inflammasomes: mechanism of assembly, regulation and signalling. Nat Rev Immunol 16: 407-420. https://doi. org/10.1038/nri.2016.58

Bufe B, Schumann T, Kappl R, Bogeski I, Kummerow C, Podgórska M, Smola S, Hoth M Zufall F (2015) Recognition of bacterial signal peptides by mammalian formyl peptide receptors: a new mechanism for sensing pathogens. I Biol Chem 290: 7369-7387. https://doi. org/10.1074/jbc.M114.626747

Cait A, Hughes MR, Antignano F, Cait J, Dimitriu PA, Maas KR, Mohn WW (2017) Microbiome-driven allergic lung inflammation is ameliorated by short-chain fatty acids. Mucosal Immunol 11: 785-795. https://doi.org/10.1038/mi.2017.75

Chang PV, Hao L, Offermanns S, Medzhitov R (2014) The microbial metabolite butyrate regulates intestinal macrophage function via histone deacetylase inhibition. Proc Natl Acad Sci USA 111: 2247-2252. https://doi.org/10.1073/pnas.1322269111

Chauvistré H, Küstermann C, Rehage N, Klisch T, Mitzka S, Felker P, Rose-John S, Zenke M, Seré K M (2014) Dendritic cell development requires histone deacetylase activity. Eur J Immunol 44: $2478-$ 2488. https://doi.org/10.1002/eji.201344150

Chow J, Mazmanian SK (2010) A Pathobiont of the Microbiota Balances Host Colonization and Intestinal Inflammation. Cell Host Microbe 7: 265-276. https://doi.org/10.1016/j.chom.2010.03.004

Chow J, Tang H, Mazmanian SK (2011) Pathobionts of the gastrointestinal microbiota and inflammatory disease. Curr Opin Immunol 23: 473-480. https://doi.org/10.1016/J.COI.2011.07.010

Claesson MJ, Cusack S, O'Sullivan O, Greene-Diniz R, de Weerd H, Flannery E, Marchesi JR, Falush D, Dinan T, Fitzgerald G, Stanton C, van Sinderen D, O'Connor M, Harnedy N, O'Connor K, Henry C, O’Mahony D, Fitzgerald AP, Shanahan F, Twomey C, Hill C, Ross RP, O'Toole PW (2011) Composition, variability, and temporal stability of the intestinal microbiota of the elderly. Proc Natl Acad Sci USA 108: 4586-4591. https://doi.org/10.1073/ pnas. 1000097107

Claesson MJ, Jeffery IB, Conde S, Power SE, O’Connor EM, Cusack S, Harris HM, Coakley M, Lakshminaravanan B, O'Sullivan O, Fitzgerald GF, Deane J, O'Connor M, Harnedy N, O'Connor K, O'Mahony D, van Sinderen D, Wallace M, Brennan L, Stanton C, Marchesi JR, Fitzgerald AP, Shanahan F, Hill C, Ross RP, O'Toole PW (2012) Gut microbiota composition correlates with diet and health in the elderly. Nature 488: 178-184. https://doi. org/10.1038/nature11319

Human Microbiome Project Consortium (2012) Structure, function and diversity of the healthy human microbiome. Nature 486: 207-214. https://doi.org/10.1038/nature11234

Cotillard A, Kennedy SP, Kong LC, Prifti E, Pons N, Le Chatelier E, Layec S (2013) Dietary intervention impact on gut microbial gene richness. Nature 500: 585-588. https://doi.org/10.1038/nature12480

D’Souza WN, Douangpanya J, Mu S, Jaeckel P, Zhang M, Maxwell JR, Hsu H (2017) Differing roles for short chain fatty acids and GPR43 agonism in the regulation of intestinal barrier function and immune responses. PLoS One 12: e0180190. https://doi.org/10.1371/journal. pone. 0180190

Duncan S H, Barcenilla A, Stewart CS, Pryde SE, Flint HJ (2002) Acetate utilization and butyryl coenzyme A (CoA):acetate-CoA transferase in butyrate-producing bacteria from the human large intestine. Appl Environ Microbiol 68: 5186-5190. https://doi.org/10.1128/ AEM.68.10.5186-5190.2002

Efendi H (2016) Clinically Isolated Syndromes: Clinical Characteristics, Differential Diagnosis, and Management. Noro Psikiyatr Ars, 52: 1-11. https://doi.org/10.5152/npa.2015.12608

Evsyutina Y, Komkova I, Zolnikova O, Tkachenko P, Ivashkin V (2017) Lung microbiome in healthy and diseased individuals. WJR 7: 39-47. https://doi.org/10.5320/wjr.v7.i2.39

Fellows R, Denizot J, Stellato C, Cuomo A, Jain P, Stoyanova E, Varga-Weisz P (2018) Microbiota derived short chain fatty acids promote histone crotonylation in the colon through histone deacetylases. Nat Commun 9: 105. https://doi.org/10.1038/s41467-017-02651-
Feng T, Cao AT, Weaver CT, Elson CO, Cong Y (2011) Interleukin-12 Cconverts Foxp3+ regulatory $\mathrm{T}$ cells to interferon- $\gamma$-producing Foxp3+ T Cells that inhibit colitis. Gastroenterology 140: 20312043. https://doi.org/10.1053/i.gastro.2011.03.009

Flemer B, Lynch DB, Brown JMR, Jeffery IB, Ryan FJ, Claesson MJ, O'Riordain M, Shanahan F, O’Toole PW (2017) Tumour-associated and non-tumour-associated microbiota in colorectal cancer. Gut 66: 633-643. https://doi.org/10.1136/gutinl-2015-309595

Fransen F, van Beek AA, Borghuis T, Aidy S El, Hugenholtz F, van der Gaast - de Jongh C, de Vos P (2017) Aged gut microbiota contributes to systemical inflammaging after transfer to germ-free mice. Fron Immunol 8: 1385. https://doi.org/10.3389/fimmu.2017.01385

Fukugaiti MH, Ignacio A, Fernandes MR, Ribeiro Júnior U, Nakano V, Avila-Campos MJ, Avila-Campos MJ (2015) High occurrence of Fusobacterium nucleatum and Clostridium difficile in the intestinal microbiota of colorectal carcinoma patients. Braz J Microbiol 46: 1135-1140. https://doi.org/10.1590/S1517-838246420140665

Gaudet RG, Sintsova A, Buckwalter CM., Leung N, Cochrane A, Li J, Cox AD, Moffat J, Gray-Owen, SD (2015) Innate immunity. Cytosolic detection of the bacterial metabolite HBP activates TIFA-dependent innate immunity. Science 348: 1251-1255. https://doi. org/10.1126/science.aaa4921

Gill PA, van Zelm MC, Muir JG, Gibson PR (2018) Review article: short chain fatty acids as potential therapeutic agents in human gastrointestinal and inflammatory disorders. Aliment Pharmacol Ther 48:15-34. https://doi.org/10.1111/apt.14689

Gomes-Neto JC, Kittana H, Mantz S, Segura Munoz RR, Schmaltz RJ, Bindels LB, Clarke J, Hostetter JM, Benson AK, Walter J, RamerTait AE (2017) A gut pathobiont synergizes with the microbiota to instigate inflammatory disease marked by immunoreactivity against other symbionts but not itself. Scientific Reports 7: 17707. https://doi. org/10.1038/s41598-017-18014-5

Grabarska A, Dmoszyńska-Graniczka M, Nowosadzka E, Stepulak A (2013) Histone deacetylase inhibitors - molecular mechanisms of actions and clinical applications. Postepy Hig Med Dosw 67: 722-735. https://doi.org/10.5604/17322693.1061381

Hesterberg RS, Cleveland JL, Epling-Burnette PK (2018) Role of polyamines in immune cell functions. Med Sci 6: 22. https://doi. org $/ 10.3390 /$ medsci6010022

Holmes E, Li JV, Marchesi J R, Nicholson JK (2012) Gut microbiota composition and activity in relation to host metabolic phenotype and disease risk. Cell Metab 16: 559-564. https://doi.org/10.1016/j. cmet.2012.10.007

Huang W, Guo HL, Deng X, Zhu TT, Xiong JF, Xu YH, Xu Y (2017) Short-chain fatty acids inhibit oxidative stress and inflammation in mesangial cells induced by high glucose and lipopolysaccharide. Exp Clin Endocrinol Diabetes 125: 98-105. https://doi. org/10.1055/s-0042-121493

Iebba V, Totino V, Gagliardi A, Santangelo F, Cacciotti F, Trancassini M, Mancini C, Cicerone C, Corazziari E, Pantanella F, Schippa S (2016) Eubiosis and dysbiosis: the two sides of the microbiota. New Microbiol 39: 1-12. http://www.ncbi.nlm.nih.gov/pubmed/26922981

Jackson MA, Jeffery IB, Beaumont M, Bell JT, Clark AG, Ley RE, O’Toole PW, Spector TD, Steves CJ (2016) Signatures of early frailty in the gut microbiota. Genome Med 8: 8. https://doi.org/10.1186/ s13073-016-0262-7

Jin UH, Lee SO, Sridharan G, Lee K, Davidson LA, Jayaraman A, Chapkin RS, Alaniz R, Safe S (2014) Microbiome-derived tryptophan metabolites and their aryl hydrocarbon receptor-dependent agonist and antagonist activities. Mol Pharmacol 85: 777-788. https:// doi.org/10.1124/mol.113.091165

Kato K, Odamaki T, Mitsuyama E, Sugahara H, Xiao J, Osawa R (2017) Age-related changes in the composition of gut bifidobacterium species. Curr Microbiol 74: 987-995. https://doi.org/10.1007/ s00284-017-1272-4

Keshelava A, Solis GP, Hersch M, Koval A, Kryuchkov M, Bergmann S, Katanaev VL (2018) High capacity in G protein-coupled receptor signaling. Nat Commun 9: 876. https://doi.org/10.1038/s41467-01802868-y

Kim KA, Jeong JJ, Yoo SY, Kim DH (2016) Gut microbiota lipopolysaccharide accelerates inflamm-aging in mice. BMC Microbiol 16: 9. https://doi.org/10.1186/s12866-016-0625-7

Kimura I, Inoue D, Maeda T, Hara T, Ichimura A, Miyauchi S, Tsujimoto G (2011) Short-chain fatty acids and ketones directly regulate sympathetic nervous system via $G$ protein-coupled receptor 41 (GPR41). Proc Natl Acad Sci 108: 8030-8035. https://doi. org/10.1073/pnas.1016088108

Kobayashi M, Mikami D, Kimura H, Kamiyama K, Morikawa Y, Yokoi S, Iwano M (2017) Short-chain fatty acids, GPR41 and GPR43 ligands, inhibit TNF- $\alpha$-induced MCP-1 expression by modulating p38 and JNK signaling pathways in human renal cortical epithelial cells. Biochem Biophys Res Commun 486: 499-505. https://doi. org/10.1016/j.bbrc.2017.03.071

Koh A, De Vadder F, Kovatcheva-Datchary P, Bäckhed F (2016) From dietary fiber to host physiology: short-chain fatty acids as key bac- 
terial metabolites. Cell 165: 1332-1345. https://doi.org/10.1016/j. cell.2016.05.041

Komiya Y, Shimomura Y, Higurashi T, Sugi Y, Arimoto J, Umezawa S, Matsumoto M Nakajima A (2018) Patients with colorectal cancer have identical strains of Fusobacterium nucleatum in their colorectal cancer and oral cavity. Gut https://doi.org/10.1136/gutjnl-2018-316661

Korek E, Krauss H (2015) Novel adipokines: their potential role in the pathogenesis of obesity and metabolic disorders. Postepy Hig Med Dosw 69: 799-810. https://doi.org/10.5604/17322693.1161415

Korem T, Zeevi D, Suez J, Weinberger A, Avnit-Sagi T, Pompan-Lo$\tan$ M, Segal E (2015) Growth dynamics of gut microbiota in health and disease inferred from single metagenomic samples. Science 349: 1101-1106. https://doi.org/10.1126/science.aac4812

Langille M G, Meehan CJ, Koenig JE, Dhanani AS, Rose RA, Howlett SE, Beiko RG (2014) Microbial shifts in the aging mouse gut. Microbiome 2: 50. https://doi.org/10.1186/s40168-014-0050-9

Le Chatelier E, Nielsen T, Qin J, Prifti E, Hildebrand F, Falony G, Pedersen O (2013) Richness of human gut microbiome correlates with metabolic markers. Nature 500: 541-546. https://doi. org/10.1038/nature12506

Le Poul E, Loison C, Struyf S, Springael J., Lannoy V, Decobecq ME, Brezillon S, Dupriez V, Vassart G, Van Damme J, Parmentier M, Detheux M (2003) Functional characterization of human receptors for short chain fatty acids and their role in polymorphonuclear cell activation. J Biol Chem 278: 25481-25489. https://doi.org/10.1074/ jbc.M301403200

Lee N, Kim WU (2017) Microbiota in T-cell homeostasis and inflammatory diseases. Exp Mol Med 49: e340. https://doi.org/10.1038/ emm.2017.36

Levy M, Thaiss CA, Zeevi D, Dohnalová L, Zilberman-Schapira G, Mahdi JA, Elinav E (2015) Microbiota-modulated metabolites shape the intestinal microenvironment by regulating NLRP6 inflammasome signaling. Cell 163: 1428-1443. https://doi.org/10.1016/j. cell.2015.10.048

Lloyd-Price J, Mahurkar A, Rahnavard G, Crabtree J, Orvis J, Hall A B, Huttenhower C (2017) Strains, functions and dynamics in the expanded Human Microbiome Project. Nature 550: 61. https://doi. org /10.1038/nature23889

Lu Y, Fan C, Li P, Lu Y, Chang X, Qi K (2016) Short chain fatty acids prevent high-fat-diet-induced obesity in mice by regulating $G$ protein-coupled receptors and gut microbiota. Sci Rep 6: 37589 . https://doi.org/10.1038/srep37589

Macia L, Tan J, Vieira A T, Leach K, Stanley D, Luong S, Mackay CR (2015) Metabolite-sensing receptors GPR43 and GPR109A facilitate dietary fibre-induced gut homeostasis through regulation of the inflammasome. Nat Commun 6: 6734. https://doi.org/10.1038/ ncomms 7734

Mackowiak PA (2013) Recycling metchnikoff: probiotics, the intestinal microbiome and the quest for long life. Front public Heal 1: 52. https://doi.org/10.3389/fpubh.2013.00052

Maffei VJ, Kim S, Blanchard E, Luo M, Jazwinski SM., Taylor CM, Welsh DA (2017) Biological aging and the human gut microbiota. J Gerontol A Biol Sci Med Sci 72: 1474-1482. https://doi.org/10.1093/ gerona/glx042

Maier L, Pruteanu M, Kuhn M, Zeller G, Telzerow A, Anderson EE, Brochado. AR, Fernandez KC, Dose H, Mori H, Patil KR, Bork P, Typas A (2018) Extensive impact of non-antibiotic drugs on human gut bacteria. Nature 555: 623-628. https://doi. org/10.1038/nature25979

Malaisé Y, Menard S, Cartier C, Gaultier E, Lasserre F, Lencina C, Guzylack-Piriou L (2017) Gut dysbiosis and impairment of immune system homeostasis in perinatally-exposed mice to Bisphenol A precede obese phenotype development. Sci Rep 7: 14472. https://doi. org/10.1038/s41598-017-15196-w

Mamantopoulos M, Ronchi F, Van Hawwermeiren F, Vieira-Silva S, Yilmaz B, Martens L, Wullaert A (2017) NLRP6- and ASC-dependent inflammasomes do not shape the commensal gut microbiota composition. Immunity 47: 339-348. https://doi.org/10.1016/j.immuni.2017.07.011

Manzanillo P, Eidenschenk C, Ouyang W (2015) Deciphering the crosstalk among IL-1 and IL-10 family cytokines in intestinal immunity. Trends Immunol 36: 471-478. https://doi.org/10.1016/j. it.2015.06.003

Maynard CL, Elson CO, Hatton RD, Weaver CT (2012) Reciprocal interactions of the intestinal microbiota and immune system. Nature 489: 231-241. https://doi.org/10.1038/nature11551

Mazmanian SK, Round JL, Kasper D L (2008) A microbial symbiosis factor prevents intestinal inflammatory disease. Nature 453: 620-625. https://doi.org/10.1038/nature07008

Milligan G, Shimpukade B, Ulven T, Hudson BD (2017) Complex pharmacology of free fatty acid receptors. Chem Rev 117: 67-110. https://doi.org/10.1021/acs.chemrev.6b00056

Miyoshi J, Bobe AM, Miyoshi S, Huang Y, Hubert N, Delmont TO, Eren AM, Leone V,Chang, E. B. (2017). Peripartum antibiotics promote gut dysbiosis, loss of immune tolerance, and inflammatory bowel disease in genetically prone offspring. Cell Rep 2: 491-504. https://doi.org/10.1016/j.celrep.2017.06.060

Moser AM, Spindelboeck W, Strohmaier H, Enzinger C, Gattringer T, Fuchs S, Khalil M (2017) Mucosal biopsy shows immunologic changes of the colon in patients with early MS. Neurol - Neuroimmunol Neuroinflammation 4: e362. https://doi.org/10.1212/ NXI.0000000000000362

Nagpal R, Tsuji H, Takahashi T, Nomoto K, Kawashima K, Nagata S, Yamashiro Y (2017) Ontogenesis of the gut microbiota composition in healthy, full-term, vaginally born and breast-fed infants over the first 3 years of life: a quantitative bird's-eye view. Front Microbiol 8: 1388. https://doi.org/10.3389/fmicb.2017.01388

Nakajima A, Nakatani A, Hasegawa S, Irie J, Ozawa K, Tsujimoto G, Kimura I (2017) The short chain fatty acid receptor GPR43 regulates inflammatory signals in adipose tissue M2-type macrophages. PLoS One 12: e0179696. https://doi.org/10.1371/journal. pone.0179696

Nakamura YK, Janowitz C, Metea C, Asquith M, Karstens L, Rosenbaum J T, Lin P (2017) Short chain fatty acids ameliorate immune-mediated uveitis partially by altering migration of lymphocytes from the intestine. Sci Rep 7: 11745. https://doi.org/10.1038/ s41598-017-12163-3

Nastasi C, Candela M, Bonefeld C M, Geisler C, Hansen M, Krejsgaard T, Woetmann A (2015) The effect of short-chain fatty acids on human monocyte-derived dendritic cells. Sci Rep 5: 16148. https://doi.org/10.1038/srep16148

Natividad, J. M., Agus, A., Planchais, J., Lamas, B., Jarry, A. C., Martin, R., Michel ML, Chong-Nguyen C, Roussel R, Straube M, Jegou S, McQuitty C, Le Gall M, da Costa G, Lecornet E, Michaudel C, Modoux M, Glodt J, Bridonneau C, Sovran B, Dupraz L, Bado A, Richard ML, Langella P, Hansel B, Launay JM, Xavier RJ, Duboc H, Sokol H (2018) Impaired aryl hydrocarbon receptor ligand production by the gut microbiota is a key factor in metabolic syndrome. Cell Metabol 28: 737-749. https://doi.org/10.1016/j. cmet.2018.07.001

Nencioni A, Beck J, Werth D, Grunebach F, Patrone F, Ballestrero A, Brossart P (2007) Histone deacetylase inhibitors affect dendritic cell differentiation and immunogenicity. Clin Cancer Res 13: 3933-3941. https://doi.org/10.1158/1078-0432.CCR-06-2903

Ni J, Wu GD, Albenberg L, Tomov VT (2017) Gut microbiota and IBD: causation or correlation? Nat Rev Gastroenterol Hepatol 14: 573. https://doi.org/10.1038/nrgastro.2017.88

Nishida A, Inoue R, Inatomi O, Bamba S, Naito Y, Andoh A (2018) Gut microbiota in the pathogenesis of inflammatory bowel disease. Clin J Gastroenterol 11: 1-10. https://doi.org/10.1007/s12328-0170813-5

Ohira H, Fujioka Y, Katagiri C, Yano M, Mamoto R, Aoyama M, Usami M, Ikeda M (2012) Butyrate enhancement of inteleukin-1ß production via activation of oxidative stress pathways in lipopolysaccharide-stimulated THP-1 cells. J Clin Biochem Nutr 50: 59-66. https://doi.org/10.3164/jcbn.11-22

Ohira H, Tsutsui W, Fujioka Y (2017) Are short chain fatty acids in gut microbiota defensive players for inflammation and atherosclerosis? Journal Atheroscler Thromb 24: 660-672. https://doi.org/10.5551/ jat.RV17006

Org E, Blum Y, Kasela S, Mehrabian M, Kuusisto J, Kangas A J, Soininen P, Wang Z, Ala-Korpela M, Hazen SL, Laakso M, Lusis AJ (2017) Relationships between gut microbiota, plasma metabolites, and metabolic syndrome traits in the METSIM cohort. Genome Biol 18: 70. https://doi.org/10.1186/s13059-017-1194-2

Park J, Goergen CJ, HogenEsch H, Kim CH (2016) Chronically elevated levels of short-chain fatty acids induce $t$ cell-mediated ureteritis and hydronephrosis. I Immunol 196: 2388-2400. https://doi, org/10.4049/jimmunol.1502046

Park J, Kim M, Kang SG, Jannasch AH, Cooper B, Patterson J, Kim $\mathrm{CH}$ (2015) Short-chain fatty acids induce both effector and regulatory $\mathrm{T}$ cells by suppression of histone deacetylases and regulation of the mTOR-S6K pathway. Mucosal Immunol 8: 80-93. https://doi. org/10.1038/mi.2014.44

Penders J, Stobberingh EE, van den Brandt PA, Thijs C (2007) The role of the intestinal microbiota in the development of atopic disorders. Allergy 62: 1223-1236. https://doi.org/10.1111/j.13989995.2007.01462.x

Perry RJ, Peng L, Barry NA, Cline GW, Zhang D, Cardone RL, Shulman GI (2016) Acetate mediates a microbiome-brain- $\beta$-cell axis to promote metabolic syndrome. Nature 534: 213-217. https://doi. org $/ 10.1038 /$ nature18309

Pluznick JL (2016) Gut microbiota in renal physiology: focus on shortchain fatty acids and their receptors. Kidney Int 90: 1191-1198. https://doi.org/10.1016/j.kint.2016.06.033

Pluznick JL, Protzko RJ, Gevorgyan H, Peterlin Z, Sipos A, Han J, Caplan MJ (2013) Olfactory receptor responding to gut microbiota-derived signals plays a role in renin secretion and blood pressure regulation. Proc Natl Acad Sci U S A 110: 4410-4415. https://doi. org/10.1073/pnas.1215927110 
Pryde SE, Duncan SH, Hold GL, Stewart CS, Flint HJ (2002) The microbiology of butyrate formation in the human colon. FEMS Microbiol Lett 217: 133-139. Retrieved from http://www.ncbi.nlm.nih. gov/pubmed/12480096

Purcell RV, Pearson J, Aitchison A, Dixon L, Frizelle FA, Keenan JI (2017) Colonization with enterotoxigenic Bacteroides fragilis is associated with early-stage colorectal neoplasia. PLOS ONE 12: e0171602. https://doi.org/10.1371/journal.pone.0171602

Qin J, Li R, Raes J, Arumugam M, Burgdorf KS, Manichanh C, Wang J (2010) A human gut microbial gene catalogue established by metagenomic sequencing. Nature 464: 59-65. https://doi. org/10.1038/nature08821

Ragsdale SW, Pierce E (2008) Acetogenesis and the Wood-Ljungdahl pathway of CO2 fixation. Biochim Biophys Acta - Proteins Proteomics 1784: 1873-1898. https://doi.org/10.1016/j.bbapap.2008.08.012

Ratsimandresy RA, Indramohan M, Dorfleutner A, Stehlik C (2017) The AIM2 inflammasome is a central regulator of intestinal homeostasis through the IL-18/IL-22/STAT3 pathway. Cell Mol Immunol 14: 127-142. https://doi.org/10.1038/cmi.2016.35

Ravillah D, Mohammed A, Qian L, Brewer M, Zhang Y, Biddick L, Steele VE, Rao CV (2014) Chemopreventive effects of an HDAC2selective inhibitor on rat colon carcinogenesis and APCmin/+ mouse intestinal tumorigenesis. J Pharmacol Exp Ther 348: 59-68. https://doi.org/10.1124/jpet.113.208645

Reichardt N, Duncan SH, Young P, Belenguer A, McWilliam Leitch C, Scott KP, Louis P (2014) Phylogenetic distribution of three pathways for propionate production within the human gut microbiota. ISME J 8: 1323-1335. https://doi.org/10.1038/ismej.2014.14

Riaz Rajoka MS, Zhao H, Li N, Lu Y, Lian Z, Shao D, Jin M, Li Q, Zhao L, Shi J (2018) Origination, change, and modulation of geriatric disease-related gut microbiota during life. Appl Microbiol Biotechnol 19: 8275-8289. https://doi.org/10.1007/s00253-018-9264-2

Rodríguez-Carrio J, Salazar N, Margolles A, González S, Gueimonde M, de Los Reyes-Gavilán CG, Suárez A (2017) Free fatty acids profiles are related to gut microbiota signatures and short-chain fatty acids. Front Immunol 8: 823. https://doi.org/10.3389/fimmu.2017.00823

Rooks MG, Garrett WS (2016) Gut microbiota, metabolites and host immunity. Nat Rev Immunol 16: 341-352. https://doi.org/10.1038/ nri. 2016.42

Sabari BR, Tang Z, Huang H, Yong-Gonzalez V, Molina H, Kong HE, Allis CD (2015) Intracellular crotonyl-coa stimulates transcription through p300-catalyzed histone crotonylation. Mol Cell 58: 203215. https://doi.org/10.1016/j.molcel.2015.02.029

Saltzman ET, Palacios T, Thomsen M, Vitetta L (2018) Intestinal microbiome shifts, dysbiosis, inflammation, and non-alcoholic fatty liver disease. Front Microbiol 9: 61. https://doi.org/10.3389/ fmicb.2018.00061
Schwiertz A, Taras D, Schäfer K, Beijer S, Bos NA, Donus C, Hardt PD (2010) Microbiota and SCFA in Lean and Overweight Healthy Subjects. Obesity 18: 190-195. https://doi.org/10.1038/oby.2009.167

Slingerland AE, Schwabkey Z, Wiesnoski DH, Jeng RR (2017) Clinical evidence for the microbiome in inflammatory diseases. Front Immunoly 8: 400. https://doi.org/10.3389/fimmu.2017.00400

Tajkarimi M., Wexler HM (2017) CRISPR-Cas Systems in Bacteroides fragilis, an Important Pathobiont in the Human Gut Microbiome. Front Microbiology 8: 2234. https://doi.org/10.3389/fmicb.2017.02234

Tao R, de Zoeten EF, Özkaynak E, Chen C, Wang L, Porrett PM, Li B, Turka LA, Olson EN, Greene MI, Wells AD, Hancock WW (2007) Deacetylase inhibition promotes the generation and function of regulatory T cells. Nat Med 13: 1299-1307. https://doi. org/10.1038/nm1652

Taylor AW (2016) Ocular immune privilege and transplantation. Front Immunol 7: 37. https://doi.org/10.3389/fimmu.2016.00037

Ticinesi A, Tana C, Nouvenne A, Prati B, Lauretani F, Meschi T (2018) Gut microbiota, cognitive frailty and dementia in older individuals: a systematic review. Clin Interv Aging 13: 1497-1511. https://doi.org/10.2147/CIA.S139163

Tramontano M, Andrejev S, Pruteanu M, Klünemann M, Kuhn M, Galardini M, Patil KR (2018) Nutritional preferences of human gut bacteria reveal their metabolic idiosyncrasies. Nat Microbiol 3: 514 522. https://doi.org/10.1038/s41564-018-0123-9

Vital M, Howe AC, Tiedje JM (2014) Revealing the bacterial butyrate synthesis pathways by analyzing (meta)genomic data. MBio 5: e00889. https://doi.org/10.1128/mBio.00889-14

Waldecker M, Kautenburger T, Daumann H, Busch C, Schrenk D (2008) Inhibition of histone-deacetylase activity by short-chain fatty acids and some polyphenol metabolites formed in the colon. J Nutr Biochem 19: 587-593. https://doi.org/10.1016/J.JNUTBIO.2007.08.002

Xiong Y, Miyamoto N, Shibata K, Valasek MA, Motoike T, Kedzierski RM, Yanagisawa M (2004) Short-chain fatty acids stimulate leptin production in adipocytes through the $G$ protein-coupled receptor GPR41. Proc Natl Acad Sci US A 101: 1045-1050. https://doi. org/10.1073/pnas.2637002100

Xu M, Pokrovskii M, Ding Y, Yi R, Au C, Harrison OJ, Littman DR (2018) c-MAF-dependent regulatory $\mathrm{T}$ cells mediate immunological tolerance to a gut pathobiont. Nature 554: 373-377. https://doi. org/10.1038/nature25500

Yuan X, Wang L, Bhat OM, Lohner H, Li PL (2018) Differential effects of short chain fatty acids on endothelial Nlrp3 inflammasome activation and neointima formation: Antioxidant action of butyrate. Redox Biol 16: 21-31. https://doi.org/10.1016/j.redox.2018.02.007

Zechner EL (2017) Inflammatory disease caused by intestinal pathobionts. Curr Opin Microbiol 35: 64-69. https://doi.org/10.1016/J. MIB.2017.01.011 